\title{
Study of Nosocomial Infections and Molecular Diagnosis of Bacterial Resistance in Patients Admitted in Intensive Care Units of Regional Cancer Center
}

\author{
Foram Maulin Patel ${ }^{*}$
}

\begin{abstract}
Department of Microbiology, The Gujarat Cancer \& Research Institute, New civil hospital, Asarwa, Ahmedabad, Gujarat, India
\end{abstract}

*Corresponding author

\begin{abstract}
A B S T R A C T
Nosocomial infection (NI) or health care associated infection is defined as an infection developing in hospitalized patients after $48 \mathrm{hrs}$, neither present nor in incubation at the time of their admission. The objectives of this study were to determine the frequency and pattern of nosocomial infection in patients admitted in ICU of tertiary cancer hospital and to detect the etiological agent with their antimicrobial resistance by molecular methods and

\section{Keywords}

Nosocomial infection, Intensive care unit

\section{Article Info}

Accepted:

06 August 2018

Available Online:

10 September 2018

also potential source of infection. This was an observational study conducted from January 2014 to March 2014. Total 100 different types of samples were collected from 330 admitted patients who developed clinical evidence of infection after $48 \mathrm{hrs}$ of admission in ICUs. Organisms causing infections were identified and they were further subjected for Antibiotic susceptibility testing by MIC and molecular diagnosis of bacterial resistance using reverse hybridization technique. During the study periods, $100(30.3 \%)$ out of 330 patients acquired nosocomial infection. Wound infection was seen in $49 \%$, followed by respiratory tract infection in $19 \%$ and blood stream infection in $16 \%$, other infections were urinary tract and gastrointestinal infections. Antibiotic resistance profile revealed that majority of bacterial isolates was resistance to multiple antibiotics. Different types of resistance mechanisms were observed in isolated organisms by molecular methods (reverse hybridization). Amongst Gram negative pathogens, $40.90 \%$ were ESBL producers, $6.81 \%$ were positive for Carbapenamases production. $25 \%$ of Gram positive cocci were MRSA positive. Patients admitted in ICUs are at higher risk of acquiring nosocomial infection. Isolated pathogens are multidrug resistant. Standard guidelines for infection prevention should be followed in ICU to reduce the nosocomial infection.
\end{abstract}

\section{Introduction}

Infection is a major factor determining clinical outcome among patients requiring intensive care unit (ICU) support. The causes of infection within ICU are multi-factorial, and consequences depend on source involved, organisms associated, underlying morbidity, timeliness and appropriateness of the treatment/interventions received. (Bhattacharya and Mondal, 2010; Chen et al., 2009) It is associated with increased morbidity 
and mortality. Nosocomial infection (NI) or health care associated infection is defined as an infection developing in hospitalized patients after $48 \mathrm{hrs}$, neither present nor in incubation at the time of their admission. (Garner et al., 1988) NI is amongst the most difficult problems confronting clinicians who deal with severally ill patients. The incidence of NI is estimated at $9-37 \%$ in tertiary care hospitals reaching up to $28 \%$ in ICU of different population and different definitions. (Cagatay et al., 2007)

Clinical profile of patients requiring intensive care support: Any clinical event, which compromises the airway, breathing, circulation (ABC) of a patient or breaches significantly the integrity and functioning of tissues and organs (post-surgery, post trauma) may results in the requirement of ICU or high dependency unit (HDU) support. (Bhattacharya and Mondal, 2010)

Sources of hospital infections: Predisposing factors for infection in the hospital are: A susceptible host, a microbe capable of producing an infection, an environment that is congenial for the multiplication of the microbe. The source of the infecting organism may be exogenous - either from another patient or a member of the hospital staff, or from the inanimate environment in the hospital; or it may be endogenous from the patient's own flora at the time of infection may include organisms brought into the hospital at admission.

Infecting organisms may spontaneously invade the tissues of the patient or may be introduced into them by surgical procedures, instrumental manipulation or nursing procedures. The inanimate environment of the hospital that acts as an important source comprises of: Contaminated air, water, food and medicaments, used equipments and instruments, soiled linen and hospital waste
(Bio medical waste). (Nosocomial Infections An Overview, 2001)

Infections among patients in the intensive care unit: Infection among ICU patients might be community acquired (viral encephalitis, bacterial meningitis, pneumonia, endocarditis, intra-visceral abscesses, and urinary tract infections-UTIs) or hospital and health care associated infections (surgical site infectionsSSIs, hospital acquired pneumonia-HAP, catheter related blood stream infectionsCRBSI, and catheter associated UTI). (Vincent et al., 1995)

\section{Common health care associated infections in intensive care unit patients: (Bhattacharya and Mondal, 2010)}

Ventilator associated pneumonia

Skin and soft tissue infection

Blood stream infections (BSIs) including catheter related

Urinary tract infection

In the past, staphylococci, Pseudomonas, and Escherichia coli have been the main cause of nosocomial infection. Nosocomial pneumonia, surgical wound infections, and vascular access-related bacteremia have caused the most illness and death in hospitalized patients; and intensive care units have been the epicenters of antibiotic resistance.

In addition to their association with increased morbidity and mortality, nosocomial infections are frequently associated with drugresistant micro-organisms, including methicillin-resistant Staphylococcus aureus (MRSA) and extended spectrum - lactamase (ESBL)-producing gram-negative bacteria, Carbapenamases producers and multi drug resistance Acinetobacter which can pose 
considerable therapeutic problems. (Vincent $e t$ al., 1995; Blamoun et al., 2009)

This study is to determine the frequency and pattern of nosocomial infection in cancer patients admitted in ICU of tertiary cancer hospital and to detect the etiological agent with their antimicrobial resistance by molecular methods and also potential source of infection.

\section{Materials and Methods}

This hospital based study was conducted at Intensive care units of The Gujarat Cancer \& Research Institute (GCRI), a tertiary cancer care hospital.

All patients who are admitted in the ICUs for more than 48 hours with different complaints and presentations and develop clinical evidence of infection that is not originate from patient's original admitting diagnosis, was included in this study. Critical patients from different oncology departments like: medical, surgical, gynecology, neurology, pediatric, nephrology, urology and emergency which referred for monitoring, observation and management were included. A performa was designed and used for data collection. This study was approved by Ethics and Scientific board of hospital.

From study periods of January 2014 to March 2014, total 100 different types of samples were collected from patients who are having history of fever after $48 \mathrm{hrs}$ of admission, like urine from urinary catheter, stool, peripheral blood, catheter blood, tracheal tube aspirate, wound secretion from surgical wound or bedsore. All samples were transferred to a microbiology laboratory by trained technicians according to standard microbiology protocol. After receiving samples in laboratory all samples were followed according to standard CLSI guidelines for identification of etiological agent using automated bacteriological system (Vitek 2 compact, Biomerieux). Antibiotic sensitivity testing was done by MIC technique using same system.

Resistance mechanism detected by molecular methods. Then organisms are subjected to DNA extraction by Nucleo pore fungus/bacteria kit (Genetix Biotech Asia Pvt. Ltd.) and then they were subjected for detection of different resistance gene by PCR and reverse hybridization method like mec A gene for MRSA, OXA family for Carbapenamases, TEM and SHV gene detection for ESBL producers using Multiplex PCR module and Multiplex Hybridization module (Krishgen biosystem).

\section{Results and Discussion}

During the study periods of January 2014 to March 2014, total of 100 patients were identified who acquired infection during their stay in all ICUs, like medical ICU, postoperative ICU, surgical ICU, bone marrow transplant unit from total 330 admitted patients.

Demographic data of patients who acquire infection are summarized in table 1 . Out of 100 patients 48 were from urban area and 52 from rural area. Patient's Unit wise data are mentioned in table 2. Common infections observed in such patients are given in Table 3.

Nosocomial infections caused by different pathogens like E. coli, Klebsiella, and Pseudomonas etc. details are given in table 4.

Prevalence of antibiotic resistance in Nosocomial infection is given in table 5. Antibiotic resistance profile revealed that majority of bacterial isolates was resistance to multiple antibiotics. Different types of resistance mechanisms were observed in isolated organisms by molecular methods. Data are given in Table 6. 
Cancer patients having treatment in intensive care units are at a higher risk of nosocomial infection due to different causes like disruption of barriers to infection by endotracheal intubation and tracheostomy, urinary bladder catheterization and central venous catheterization.

\section{Nosocomial infection in critical areas}

The percentages of nosocomial infection in our study were $30.30 \%$. In recent study by Muhammad et al., the frequency of nosocomial infection in Immunocompromised patients in ICU was $39.7 \%$. (Muhammad et al., 2008)

Common infections observed in ICUs are wound infection, respiratory infection including VAP, bloodstream infection, urinary tract and gastrointestinal infections. The most common infection in ICU was wound infection $(49 \%)$ followed by respiratory infection (19\%).

Wound infection is the most common because surgical patients are highest admitted in ICU (49/100). Most common isolated organism from wound infection is E. coli followed by Pseudomonas.

Nosocomial pneumonia is the second most common nosocomial infection in critical patients. Frequencies of VAP reported in different studies are 9\%, 18\% and $21 \%$. In current study, $19 \%$ patients acquired VAP in ICU.

The predominant pathogens causing VAP are Pseudomonas aeruginosa, Acinetobacter baumanii, Klebsiella, coagulase negative Staphylococcus.

Blood stream infection is also a common infection observed in ICU patients. Frequency of blood stream infection in our study was $16 \%$, while in the study by (Muhammad et al., 2008 ) it was $27 \%$.

It was high in their study because study was conducted amongst nephrology patients.

The pathogens isolated from these patients are Klebsiella, E. coli, Pseudomonas aeruginosa, Burkholderia and Staphylococcus aureus.

In our study, urinary tract infection found in 10 patients, was caused by E. coli, Pseudomonas and Klebsiella. And gastrointestinal infection in six patients caused by E. coli.

Prevalence of antibiotic resistance in nosocomial infection

Antibiotic resistance profile revealed that majority of bacterial isolates was resistance to multiple antibiotics (Table 5).

More than $50 \%$ of $E$. coli was resistant to all B-lactams and B-lactams inhibitors, Quinolones. Klebsiella shows 70\% resistance to B-lactams and B-lactams inhibitors, Quinolones and to amino glycosides.

Acinetobacter shows $50 \%$ resistance to amino glycosides, Quinolones and to Imipenem. Resistance to antibiotics in Gram positive bacteria was less as compared to Gram negative pathogens. In the study conducted by (Kailash Mulchandani et al., 2017) from south India shows similar resistance pattern in ICU.

In their study E. coli shows $60-90 \%$ of resistance to B-lactams and B-lactams inhibitors, Quinolones and to amino glycosides. Klebsiella and Acinetobacter show $44-83 \%$ and $45-90 \%$ of resistance to same class of antibiotics respectively. 
Table.1 Demographic data of patients $(n=100)$

\begin{tabular}{|c|c|c|c|}
\hline Sr no. & Age group (in yrs.) & Male (Number) & Female (Number) \\
\hline $\mathbf{1}$ & $1-10$ & 4 & 3 \\
\hline $\mathbf{2}$ & $11-20$ & 3 & 0 \\
\hline $\mathbf{3}$ & $21-30$ & 6 & 6 \\
\hline $\mathbf{4}$ & $31-40$ & 5 & 7 \\
\hline $\mathbf{5}$ & $41-50$ & 10 & 11 \\
\hline $\mathbf{6}$ & $51-60$ & 11 & 19 \\
\hline $\mathbf{7}$ & $61-70$ & 9 & 4 \\
\hline $\mathbf{8}$ & $71-80$ & 1 & 1 \\
\hline
\end{tabular}

Table.2 Patient's unit wise data $(n=100)$

\begin{tabular}{|c|c|c|}
\hline Sr. No & Unit of referral & Number \\
\hline 1 & Surgery & 45 \\
\hline 2 & Medicine & 21 \\
\hline 3 & Gynecology & 16 \\
\hline 4 & Pediatric & 10 \\
\hline 5 & Neurology & 8 \\
\hline
\end{tabular}

Table.3 Pattern of nosocomial infection in critical care areas $(n=100)$

\begin{tabular}{|c|l|l|c|}
\hline Sr. No & \multicolumn{1}{|c|}{ Type of infection } & \multicolumn{1}{|c|}{ Type of samples received } & Number \\
\hline $\mathbf{1}$ & Wound infection & Pus, Pus Swab & 49 \\
\hline $\mathbf{2}$ & Respiratory infection & Sputum, BAL, ET secretion, Tracheostomy tip, ET tip etc. & 19 \\
\hline $\mathbf{3}$ & Blood stream infection & Peripheral and Catheter blood & 16 \\
\hline 4 & Urinary tract infection & Urine & 10 \\
\hline 5 & Gastrointestinal infection & Stool & 6 \\
\hline
\end{tabular}

Table.4 Nosocomial infection caused by different pathogens $(n=100)$

\begin{tabular}{|c|c|c|c|c|c|c|c|}
\hline $\begin{array}{l}\text { Sr. } \\
\text { No }\end{array}$ & Organism & $\begin{array}{l}\text { Wound } \\
\text { infection }\end{array}$ & $\begin{array}{c}\text { Respiratory } \\
\text { infection }\end{array}$ & $\begin{array}{c}\text { Blood } \\
\text { stream } \\
\text { infection }\end{array}$ & $\begin{array}{c}\text { Urinary } \\
\text { tract } \\
\text { infection }\end{array}$ & $\begin{array}{c}\text { Gastro- } \\
\text { intestinal } \\
\text { infection }\end{array}$ & Total \\
\hline 1 & E. coli & 21 & 2 & 3 & 6 & 6 & 38 \\
\hline 2 & Klebsiella & 7 & 4 & 4 & 2 & 0 & 17 \\
\hline 3 & Pseudomonas aeruginosa & 8 & 4 & 2 & 2 & 0 & 16 \\
\hline 4 & Acinetobacter & 6 & 4 & 1 & 0 & 0 & 11 \\
\hline 5 & Enterobacter & 2 & 2 & 0 & 0 & 0 & 4 \\
\hline 6 & Burkholderia & 0 & 0 & 2 & 0 & 0 & 2 \\
\hline 7 & S.aureus & 2 & 0 & 2 & 0 & 0 & 4 \\
\hline 8 & CONS & 3 & 3 & 2 & 0 & 0 & 8 \\
\hline & Total & 49 & 19 & 16 & 10 & 6 & 100 \\
\hline
\end{tabular}


Table.5 Prevalence of antibiotic resistance in nosocomial infection
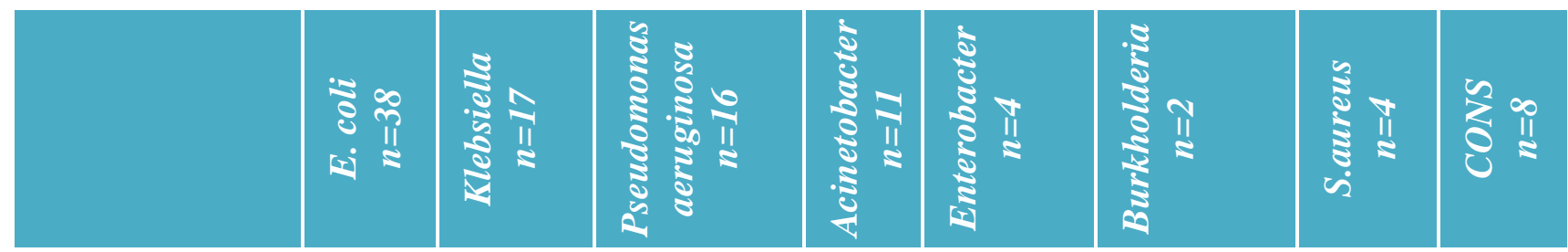

\begin{tabular}{|l|}
\hline Antibiotics \\
\hline B-lactam \\
\hline Ampicillin \\
\hline Amoxicillin/ \\
Clavulanic \\
\hline Acid \\
\hline
\end{tabular}

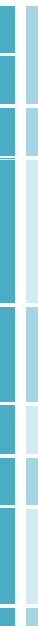

\begin{tabular}{l|}
\hline Piperacillin/ \\
Tazobactum \\
\hline Cefuroxime \\
\hline Ceftrioxone \\
\hline Cefoparazone/ \\
Sulbactum \\
\hline Cefepime \\
\hline
\end{tabular}

\begin{tabular}{|l|l|l|l|l|}
\hline 20 & 11 & 0 \\
\hline 14 & 10 & 0 \\
\hline
\end{tabular}

$$
\mathrm{N}=100
$$

\begin{tabular}{|c|c|c|c|c|c|c|c|}
\hline 12 & 9 & 4 & 2 & 2 & 1 & 0 & 0 \\
\hline 22 & 11 & 0 & 0 & 1 & 1 & 0 & 0 \\
\hline 22 & 11 & 0 & 0 & 1 & 1 & 0 & 0 \\
\hline 10 & 9 & 5 & 3 & 2 & 1 & 0 & 0 \\
\hline 27 & 11 & 5 & 6 & 2 & 1 & 0 & 0 \\
\hline
\end{tabular}

\section{Amino \\ glycosides}

\begin{tabular}{|l|}
\hline Amikacin \\
\hline Gentamycin \\
\hline Quinolones \\
\hline Ciprofloxacin \\
\hline Levofloxacin \\
\hline Carbapenems \\
\hline
\end{tabular}

Carbapenems

\begin{tabular}{|l|}
\hline Imipenem \\
\hline Meropenem \\
\hline Ertapenem \\
\hline Others \\
\hline
\end{tabular}

\section{Aztreonam}

Minocycline Tigycycline

\begin{tabular}{|c|c|c|c|c|c|c|c|}
\hline 4 & 9 & 4 & 3 & 2 & 1 & 0 & 0 \\
\hline 14 & 8 & 3 & 7 & 2 & 1 & 3 & 5 \\
\hline & & & & & & & \\
\hline 24 & 12 & 4 & 7 & 1 & 0 & 3 & 4 \\
\hline 2 & 3 & 5 & 6 & 2 & 2 & 2 & 3 \\
\hline
\end{tabular}

\begin{tabular}{|l|l|l|l|l|l|l|l|}
\hline 5 & 9 & 4 & 6 & 2 & 1 & 3 & 5 \\
\hline 5 & 9 & 3 & 2 & 2 & 1 & 2 & 4 \\
\hline 3 & 7 & 0 & 0 & 0 & 0 & 0 & 0 \\
\hline 0 & 0 & 0 & 4 & 1 & 0 & 0 & 0 \\
\hline 0 & 0 & 8 & 2 & & 0 & 0 & 0 \\
\hline 0 & 4 & 8 & 2 & 1 & 0 & 0 & 0 \\
\hline
\end{tabular}

Table.6 Resistance mechanism in isolated organisms by molecular methods

\begin{tabular}{|c|c|c|c|c|}
\hline Sr. No & Organism Group & Resistance pattern & Number & $\%$ \\
\hline 1 & GNB & ESBL & 36 & 40.90 \\
\hline 2 & $(\mathrm{n}=88)$ & Carbapenamases & 6 & 6.81 \\
\hline 3 & GPC & MRSA & 2 & 16.6 \\
\hline 4 & $(\mathrm{n}=12)$ & VRSA & 0 & 0 \\
\hline
\end{tabular}


Antibiotic resistance mechanism in isolated pathogens

Amongst Gram negative pathogens, 40.90\% were ESBL producers, $15.90 \%$ were AmpC producer and 4.54 to $6.81 \%$ were positive for Carbapenamases production.

$25 \%$ of Gram positive cocci were MRSA positive.

Infections that develop in people who have cancer or who are getting cancer treatment can be more serious than those in people who are otherwise healthy.

They can also be harder to treat. Joint efforts of microbiologist and clinicians can save more lives.

Key action plan of clinical microbiology for infection control in ICUs (Bhattacharya and Mondal, 2010).

Regular Rounds in ICU by microbiologist (The Royal College of Pathologist, 2005).

Prompt information about critical microbiology results

Change, stoppage and optimization of antibiotic therapy as per local antibiotic policy

Use of 'Care bundles' in ICU for management of ICU infection (Khan et al., 2009; Career et al., 2008; Touati et al., 2009)

Antibiotic resistance, audit and policy implantation. (Ferrer et al., 2008)

We concluded that,

Critically ill cancer patients admitted to ICU are at a greater risk of acquiring nosocomial infection.
The common infections observed in our study were wound infection, nosocomial pneumonia including VAP, blood stream infection.

E. coli, Klebsiella and Pseudomonas were most common pathogens in ICU, and they were multidrug resistant.

Production of ESBL and Carbapenamases were high in ICU pathogens.

It is suggested that proper nursing care, sterilization and disinfection of equipments and proper handling of invasive devise are the best guidelines to control ICU infection.

And also education and awareness among health care workers as well as adherence to standard guidelines for prevention of nosocomial infection should be used to reduce frequency of nosocomial infection in intensive care unit.

Further studies regarding surveillance of nosocomial infection are required and it will play an important role in the monitoring of infection and assessment of action plans to prevent ICU infection.

\section{References}

Bhattacharya S, and Mondal AS. Clinical microbiology in the intensive care unit: Strategic and operational characteristics. Indian Journal of Medical Microbiology 2010; 28: 5-10

Blamoun J, Alfakir M, Rella ME, et al., Efficasy of an expanded ventilator bundle for the reduction of VAP in the medical ICU. Am J Infect Control 2009; 37: $172-5$

Cagatay AA, Ozcan PE, Gulec L. Risk factors for mortality of nosocomial bacteremia in ICU. Med Princ Pract 2007; 16: 18792 
Career A, Laseel L, Fortineau N. Outbreak of CTX-M-15 producing Klebsiella pneumonia controlled by cohorting patients and reinforcing infection control measure. Infect Control Hosp Epidemiology 2008; 29: 517-24

Chen YY, Wang FD, Liu CY, Chou P. Incidence rate and variable cost of nosocomial infections in different types of ICu. Infect Control Hosp Epidemiol 2009; 30: 39-46

Ferrer R, Artige A, Levy MM, Blanco J. Edusepsis study Group. Improvement in process of care and outcome after a multicenter severe sepsis educational program in Spain. JAMA 2008; 299: 2294-303

Garner JS, Jarvis WR, Emori TG, et al., CDC definations for nosocomial infection 1988. Am J Infect Control 1988; 16: $128-40$

Khan A, Lampitoc M, Salaripour M. Rapid control of a MRSA outbreak in medical ICU. Can J Infect Control 2009; 24: 126

Muhammad JS, Devrajani BR, Zulfiquar S, et $a l$., Frequency, pattern and etiology of nosocomial infection in intensive care unit: an experience at a tertiary care hospital. J Ayub Med Coll Abbottabad 2008; 20(4): 37-40

Mulchnadani K., Shastri AS, Deepashree R, et al., Antimicrobial resistance surveillance among intensive care units of a tertiary care hospitals in southern India. J Clin Diagn Res 2017; 11(2): 1-7 Nosocomial Infections - An Overview by S Krishna Prakash. Maulana Azad Medical College, New Delhi. 2001

The Royal College of Pathologist. Specimen job description: consultant medical microbiologist. April 2005

Touati A, Achour W, Cherif A Outbreak of Acinetobacter baumanii in a neonatal intensive care unit: Antimicrobial susceptibility and genotyping analysis. Ann Epidemiol 2009; 19: 372-8

Vincent JL, Bihari DJ, Suter PM et al., The prevalence of nosocomial infection in intensive care units in Europe. Results of the European Prevalence of Infection in Intensive Care (EPIC) Study. EPIC International Advisory Committee. JAMA 1995; 274: 639-44

Wip C, and Napolitano L. Bundle to prevent VAP: How valuable are they? Curr Opin Infect Dis 2009; 22: 159-66

\section{How to cite this article:}

Foram Maulin Patel. 2018. Study of Nosocomial Infections and Molecular Diagnosis of Bacterial Resistance in Patients Admitted in Intensive Care Units of Regional Cancer Center. Int.J.Curr.Microbiol.App.Sci. 7(09): 702-709. doi: https://doi.org/10.20546/ijcmas.2018.709.084 